\title{
AN ERGONOMIC ANALYSIS OF THE LADDER CLIMBING ACTIVITY
}

\author{
Donald S. Bloswick \\ Department of Mechanical Engineering, University of Utah, Salt Lake City, UT 84112, U.S.A. \\ and Don B. Chaffin \\ Center for Ergonomics, University of Michigan, Ann Arbor, MI 48109-2117, U.S.A.
}

(Received August 12, 1988; accepted in revised form November 20, 1989)

\begin{abstract}
Injuries from slips, falls and overexertion during ladder climbing activities are common in both occupational and non-occupational environments. Little is known, however, about the task, equipment, and user parameters which may cause these injuries. In order to evaluate the hazards associated with ladder climbing, ten male subjects were tested under combinations of ladder rung separation, ladder slant, climbing speed, and climbing direction.

Hand and foot forces, hand torques, torso muscle EMGs and hand and foot locations on the ladder rungs were recorded. A biomechanical model was developed which allowed the evaluation of dynamic joint moments and back forces. Study results include safety and biomechanical design guidelines relating to the effect of the task, equipment, and user parameters on climbing safety.

Under the conditions studied there does not appear to be a significant slip hazard for people with reasonable strength and mobility. There may be a potential for climber grip strength to be exceeded under some field conditions and foot slip is possible during the use of vertical ladders. There is also the potential for localized fatigue in muscles acting at the elbow, hip and ankle joints during long climbs. The relatively high measured torso muscle IEMG suggests that certain ladder climbing activities may generate considerable back forces.
\end{abstract}

\section{RELEVANCE TO INDUSTRY}

Injuries resulting from slips/falls and overexertion during ladder climbing occur frequently in occupational and non-occupational activities. This study attempts to address some of the associated risk factors and present some guidelines for ladder selection and use.

\section{KEYWORDS}

Ladder, climbing, slip, fall, low back

\section{INTRODUCTION}

Climbing activities are performed as part of many occupational tasks. Injuries from slips and falls or overexertion during climbing activities on ladders frequently result in significant medical expenses and workers compensation costs. According to the U.S. Consumer Product Safety 
Commission, there were 211,000 injuries associated with ladders in the U.S.A. in 1975 (ANSI, 1983). Snyder (1977) noted that in California between 1966 and 1973, ladders accounted for 31\% of all falls in the construction industry. In a study by Safety Sciences (1978) it was noted that approximately $8 \%$ of a sample of 500 occupational falls surveyed in the United States occurred from ladders.

While nearly all employees are exposed to varying risks associated with walking surfaces (and probably stairs) for a major part of the day, only a fraction of the population is exposed to ladders or other climbing systems, and then only for a fraction of the workday. With this in mind, the relatively high frequency of ladder injuries suggests that a significant hazard exists in work associated with ladder climbing activities.

Little research, however, has been performed to systematically analyze ladder climbing. The relationships between the climbing task, ladder, and user characteristics have not been studied, and the slip/fall hazard, overexertion injury hazard, and back injury hazard have not been quantified.

The objective of this research was to determine how slip/fall and low back hazards vary as a function of equipment variables (rung separation, ladder slant), task variables (climbing speed and direction), and user anthropometry.

A basic premise of this research is that the measured forces at the hands and the feet and the

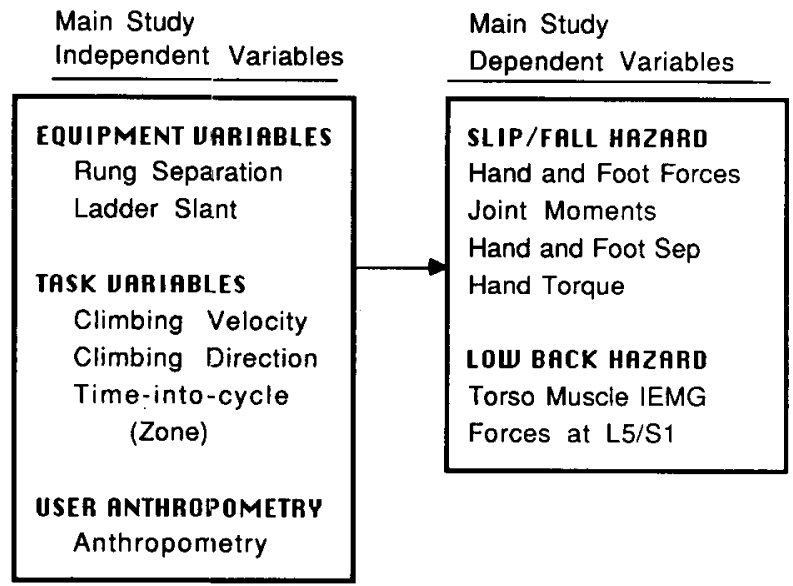

Fig. 1. Independent and dependent variables used in the study. model-estimated required moments at the elbow, shoulder, hip, knee and ankle are primary considerations in the quantification of the slip/fall hazard in a climbing activity. Joint moments are assumed to relate to the slip/fall hazard and may also predict the potential for overexertion at a particular joint. Additional considerations relating to the slip/fall hazard are the generated hand torques on the rungs and the hand and foot separation preferred by the subjects during the use of the ladder. It is also assumed that the low back hazard in the climbing activity may be stated in terms of the model-estimated forces at the L5/S1 disc and the measured IEMG activity of the torso muscles during climbing.

\section{METHODS}

\section{Experimental design}

Based on the results of an informal pilot study, it was determined that ladder slant, rung separation, climbing velocity, and climbing direction required further investigation. Each variable was studied at two levels except for ladder slant (the effect of which was highly significant in the pilot study) which was investigated at four levels. "Time-into-cycle" was included to determine how the dependent variables vary over the step cycle. Subject muscle strengths were measured for each major body joint, but were not used as a subject selection criteria. The independent and dependent variables included in the study are summarized on Fig. 1.

The levels of the independent variables included in the main study were:

Rung separation (2): 12 in., 15 in. $(30.5 \mathrm{~cm}$, $38.1 \mathrm{~cm}$ )

Ladder slant (4): $\quad 0,10,15,20 \mathrm{deg}$

Climbing velocity (2): $12 \mathrm{in.} / \mathrm{s}, 20 \mathrm{in./s} \mathrm{(30.5}$ $\mathrm{cm}, 50.8 \mathrm{~cm}$ )

Climb direction (2): up, down

Time-into-cycle: one hand and one foot on rung, both feet and both hands on rungs, other hand and foot on rung, both feet and both hands on rungs 
Anthropometry:

tall-light, tall-heavy, short-light, short-heavy, avarage $(2$ subjects in each category)

A full factorial design was used. Each of the ten subjects was tested under each of the 32 combinations of task and equipment variables.

\section{Equipment}

The ladder climbing system included seven rungs, four rungs instrumented with strain gage load cells to measure both forces and hand torques, and three rungs instrumented to measure only forces. In this study is was assumed that the $X$ (left-right) force was negligible as discussed by Chaffin and Stobbe (1979) so only $Z$ (up-down), and $Y$ (anterior-posterior) forces were recorded. Ladder slant could be easily adjusted from vertical ( 0 deg slant) to $20 \mathrm{deg}$ slant, and the rung separation could be adjusted in 1 in. $(2.5 \mathrm{~cm})$ increments. The ladder rungs were $1.25 \mathrm{in} .(3.2 \mathrm{~cm})$ in diameter, and the maximum allowable hand and foot separation, in the $X$ or left-right direction, was $31 \mathrm{in.}(78.7 \mathrm{~cm})$.

The data acquisition system consisted of the instrumented ladder noted above, an IEMG recording system, an optoelectric position detection system (SELSPOT), HP 1000 computer, and VCR to record hand and foot separation.

The climbing and data acquisition system is illustrated in Fig. 2.

\section{Subjects}

The ten male subjects used in this study included two subjects in each of the five different anthropometric categories noted earlier as defined by the 25 and 75 percentile limits of the 18-44 year old U.S. male population (NCHS, 1979).

Static muscle strengths of the subjects were determined for elbow flexion, shoulder extension, hip extension, knee extension, and ankle plantar flexion based on the methodology developed by Stobbe (1982). The subjects were seated and constrained with seat belts and straps to minimize the effect of posture on the articulation strength being measured. A 90 deg included angle at the joint was used since that approximated the angle at which maximum joint moments were observed during the climbing activity. Each subject was given three trials for each articulation.

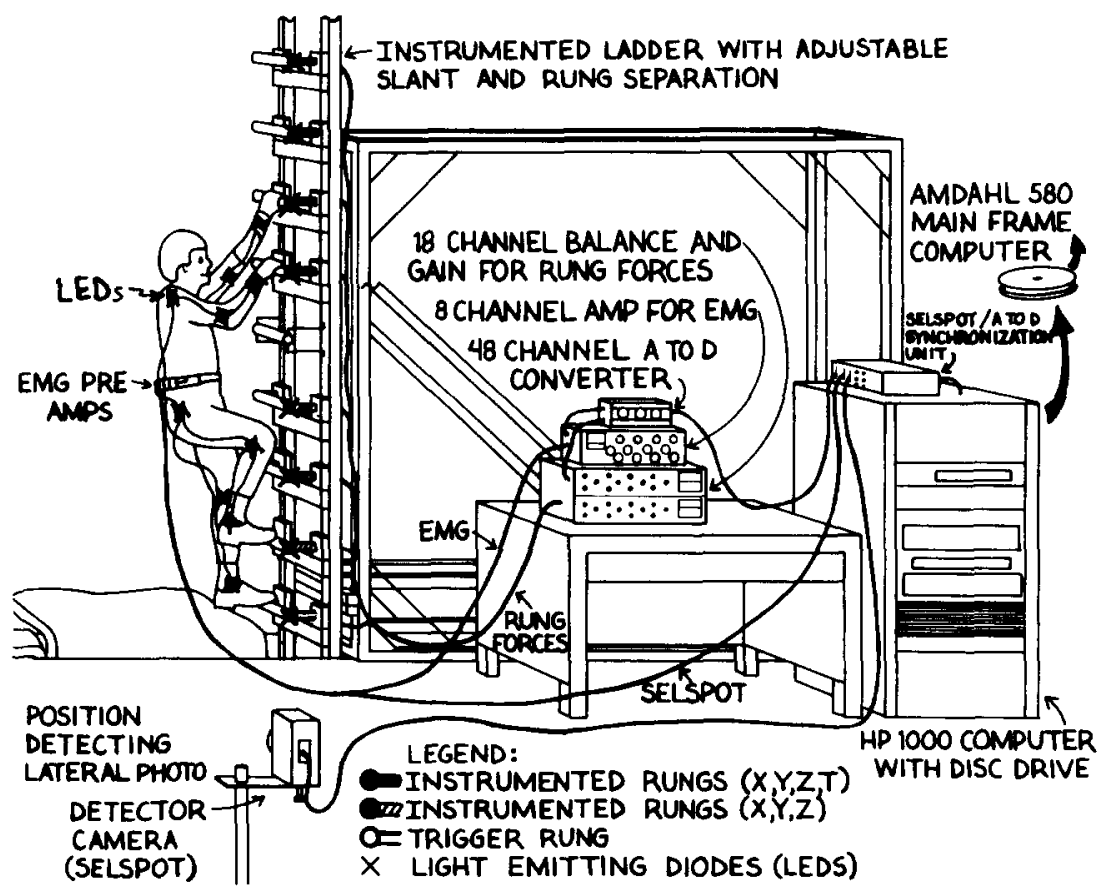

Fig. 2. Schematic of climbing data acquisition system. 


\section{Procedure}

Each subject was tested over $1 \frac{1}{2}$ day period. During the first half day anthropometry and articulation muscle strengths of the subject were recorded, the subject was made familiar with the climbing system, and was trained in the lateral gait climbing method. (In the lateral gait climbing method the arm and leg on the same side of the body move at approximately the same time.) On the second day, after a comprehensive calibration period, the subject performed 32 ladder ascents/ descents. Within the rung separation the four ladder slants were run in a randomized fashion, and within each combination of separation/slant, four randomized trials (up/down and fast/slow) were run. The data was samples at $25 \mathrm{~Hz}$.

Each subject began a trial at the signal from the experimenter and timed his gait by a metronome. At least two minutes rest was provided between trials. If the subject's heart rate was elevated at the end of a rest period additional rest was provided. A video tape record was made of each trial to allow determination of hand and foot separation.

\section{Biomechanical model}

A biodynamic model was developed to allow the prediction of articulation moment and back compressive force as a function of subject anthropometry, body link location and acceleration data, and measured hand and foot forces during the climbing activity. The model is based on the principles presented by Chaffin and Andersson (1984). A schematic of the biomechanical model input/ output is shown on Fig. 3 .

The articulation moments were predicted by working "inward" from the hands to the elbows and shoulders and from the feet to the ankles, knees, and hips. The reactive forces and moments at the proximal end of each link were calculated as a function of the resultant forces and moments at the distal end of that link, the angular acceleration of the link and the linear acceleration of the center of mass of that link. Through the application of a finite impulse response digital filter (band limited differentiator) the recorded joint displacement data were used to calculate the acceleration of each of the link centers of mass (McClellan and Parks, 1973). This method of joint moment estimation was first reported by Bresler and Frankel (1948) and has been used extensively to predict the moments at body articulations during normal walking. A more detailed notation of this procedure is contained in Appendix A.

The compressive and shear force at the L5/S1 disc is a function of the contractions in the trunk muscles required to balance the moments about

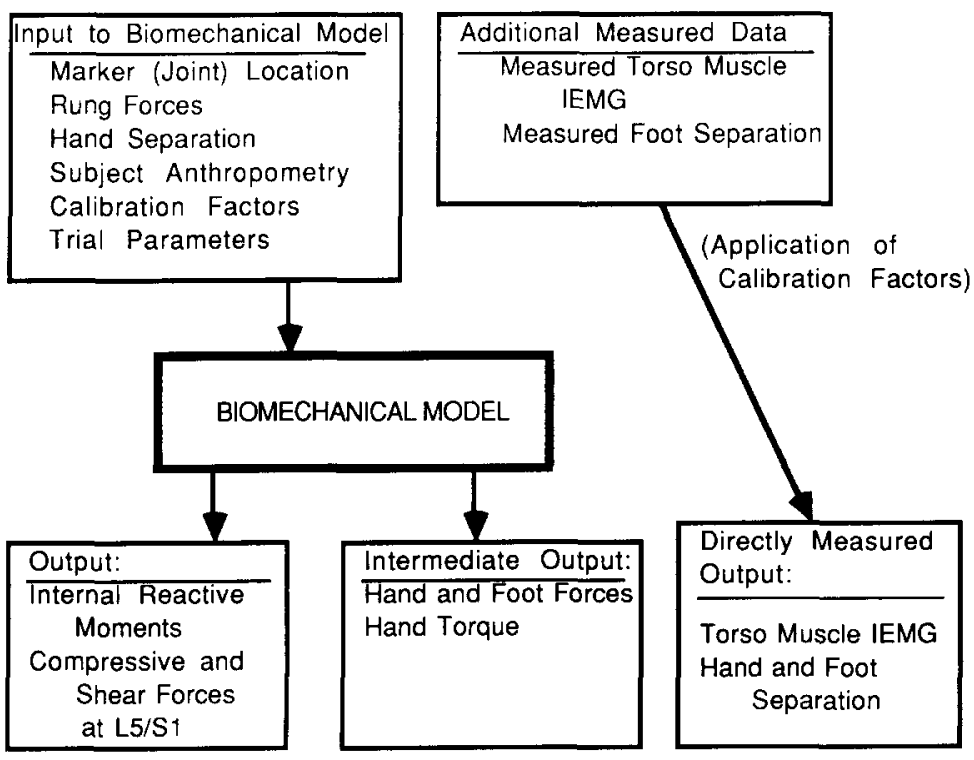

Fig. 3. Biomechanical model input/output. 
TABLE 1

Importance (percent variation explained by independent variables) and significance of dependent variables used in the study

\begin{tabular}{|c|c|c|c|c|c|c|}
\hline & $\begin{array}{l}\text { Rung } \\
\text { separation }\end{array}$ & $\begin{array}{l}\text { Ladder } \\
\text { slant }\end{array}$ & $\begin{array}{l}\text { Climbing } \\
\text { speed }\end{array}$ & $\begin{array}{l}\text { Climbing } \\
\text { direction }\end{array}$ & $\begin{array}{l}\text { Time } \\
\text { into cycle }\end{array}$ & Anthropo \\
\hline Total hand force & 0 & $47 * * *$ & $1 * * *$ & 0 & $9 * * *$ & $4 * * *$ \\
\hline Total foot force & $1 *$ & $4 * * *$ & 0 & 0 & $61 * * *$ & $1 *$ \\
\hline Hand force $Y$ & 0 & $34 * * *$ & $1^{*}$ & 0 & $14 * * *$ & $5 * * *$ \\
\hline Hand force $Z$ & $1 * * *$ & $48 * * *$ & $1 * * *$ & 0 & $2 * * *$ & $11 * * *$ \\
\hline Foot force $Y$ & 0 & $18 * * *$ & 0 & 0 & $22 * * *$ & $23 * * *$ \\
\hline Foot force $Z$ & $1 *$ & $6 * * *$ & 0 & 0 & $58 * * *$ & $2 * *$ \\
\hline Hand torque & 0 & $20 * * *$ & 0 & $6 * * *$ & $3 * * *$ & $13 * * *$ \\
\hline Hand separation & 0 & $1 * * *$ & $1 * * *$ & 0 & 0 & $58 * * *$ \\
\hline Foot separation & 0 & $6 * * *$ & $1 * *$ & $3 * * *$ & 0 & $52 * * *$ \\
\hline Elbow moment & 0 & $29 * * *$ & 0 & 1 & $8 * * *$ & $6 * * *$ \\
\hline Shoulder moment & 0 & 0 & $1 * * *$ & 1 & $21 * * *$ & $15 * * *$ \\
\hline Hip moment & 0 & 2 & 0 & $1 * * *$ & $27 * * *$ & $24 * * *$ \\
\hline Knee moment & 0 & 1 & 0 & 2 & $14 * * *$ & $33 * * *$ \\
\hline Ankle moment & 0 & $9 * * *$ & 0 & 0 & $15 * * *$ & $45 * * *$ \\
\hline Back comp force & 0 & $10^{* * *}$ & $1 * * *$ & 0 & $11 * * *$ & $9 * * *$ \\
\hline Back shear force & $2 * * *$ & $35 * * *$ & 0 & 0 & $7 * * *$ & $23 * * *$ \\
\hline Total back force & 0 & 0 & $1 * *$ & 0 & $12 * * *$ & $15 * * *$ \\
\hline Right erector IEMG & 0 & $1 * *$ & $8 * * *$ & 0 & $10 * * *$ & $36 * * *$ \\
\hline Left erector IEMG & 0 & $1 * * *$ & $6 * * *$ & $1 * * *$ & $7 * * *$ & $38 * * *$ \\
\hline
\end{tabular}

Note: ${ }^{*}=$ significant at $0.1,{ }^{* *}=$ significant at 0.01 , and $* * *=$ significant at 0.001

the lower back caused by the external forces acting on the body. Since the climbing activity involves nonsymmetric hand and foot forces, the modeling of the trunk musculature must include trunk rotators (internal and external oblique muscles). A three dimensional trunk muscle model developed by Schultz and Andersson (1981) was adapted for use in this study. The model includes seven muscle forces (right and left erector spinae, left and right internal oblique, left and right external oblique, and rectus abdominus), abdominal pressure force, and three internal forces (compressive and $X$ and $Y$ shear forces at the L5/S1 disc). Only the abdominal pressure force can be calculated leaving ten unknows and a maximum of six equations of equilibrium. The system is therefore indeterminate and principles of optimization are used to solve the system of equations and determine the force contributed by each muscle.

The optimization model minimizes the total muscle force subject to the following constraints: 1. The moments generated by the torso muscles about the L5/S1 disc must resist the external moment,

2. Maximum muscle activity is $100 \mathrm{~N} / \mathrm{cm}^{2}$,

3. Mucles can only generate tensile forces in contraction.
A more detailed discussion of this optimization procedure is contained in Appendix B.

The predictive accuracy or validity of the biomechanical model was estimated by comparing the torso muscle force predicted by the model to the torso muscle activity recorded by the EMG system. An internal check was made of the predicted articulation moments to assure that, at each point in time, the hip moment calculated from the hands to the hips approximates the hip moment calculated from the feet to the hips.

\section{RESULTS}

The results are presented in terms of the slip/fall hazard (hand/foot forces and joint moments) and low back hazard associated with the ladder climbing activities being studied. The limitations of the measurement system and the validity of the model in predicting joint moments and back forces is discussed. The effect of ladder slant on the mean values of the dependent variables is presented graphically. The effect of other independent variables is discussed in the text. Table 1 represents the importance (percent of variation in each dependent variable explained by each inde- 
pendent variable) and the significance of the results.

\section{Hand and foot forces, hand torque, hand and foot separation}

The mean total and directional (vertical and horizontal) hand force and foot force (as a percentage of subject body weight) acting on one side of the body were analyzed. These variables appeared to more accurately represent the slip hazard in the climbing activity than the hand or foot forces acting on both hands or both feet at any particular time.

Ladder slant explained $47 \%$ of the variation in mean hand forces and $4 \%$ of the variation in mean foot forces. The time-into-cycle explained $9 \%$ of the variation in mean hand forces and $61 \%$ of the variation in mean foot forces. Both ladder slant and time-into-cycle were significant at 0.001 . Rung separation, climbing speed, and climbing direction were not important in that they explained only about $1 \%$ of the variation in hand and foot forces. The anthropometry of the subjects accounted for a significant percentage of the variation in the directional forces (up to $23 \%$ for the $Y$ foot force), but the implications of this effect are unclear. The variation in the magnitude and direction of the hand and foot forces with slant are illustrated in Figs. 4 and 5, respectively.

Figures 4 and 5 indicate that as the ladder slanted from vertical the support was transferred from the hands to the feet. The hand force in the vertical and horizontal directions both decreased resulting in a decrease in the total hand force (and

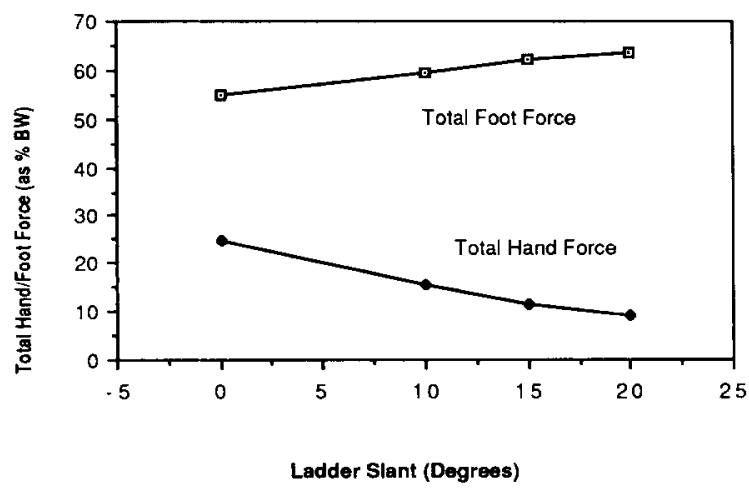

Fig. 4. Total hand and foot forces (as percent of body weight) by ladder slant.

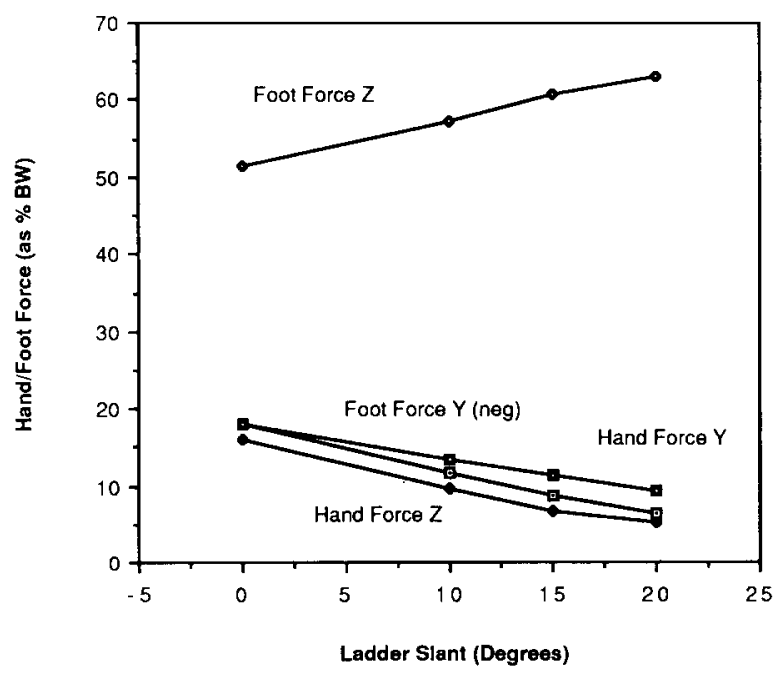

Fig. 5. Directional hand and foot forces (as percent of body weight) by ladder slant.

hand slip potential). As the ladder slanted from vertical there was an increase in vertical foot force and a decrease in horizontal foot force also resulting in a decrease in slip potential.

A further analysis of the hand forces indicated that they reached a peak of nearly $30 \%$ of body weight during the one-limb phase of the vertical ladder climbing activity. This approaches the estimate of $35 \%$ of body weight which was found to be the mean grip strength on a slippery hand rail of 0.875 in. $(2.2 \mathrm{~cm}$ ) diameter (Jack et al., 1978). There would appear to be a potential hand slip problem if the climber ascends or descends a slippery vertical ladder using his/her normal climbing pattern.

The torque generated on the rung by the hands varied to some degree with ladder slant $(20 \%)$, climbing direction $(6 \%)$, time-into-cycle $(3 \%)$ and anthropometry (13\%). Each of these independent variables was significant at 0.001 . A further analysis of these effects indicated that during the use of vertical ladders this torque may exceed $60 \%$ of the hand torque capability measured on a similar handle (Pheasant and O'Neill, 1975).

While the absence of foot angle data makes it difficult to state conclusively that there is a foot slip potential, an analysis of the horizontal and vertical foot forces indicates a horizontal/vertical force ratio of 0.40 .

The subjects demonstrated an average preferred hand separation of 12.7 in. $(32.3 \mathrm{~cm})$ and pre- 
ferred foot separation of 7.9 in. $(20.1 \mathrm{~cm})$. Shortheavy subjects had a significantly (at 0.001 ) wider preferred hand and foot separation of $15.7 \mathrm{in}$. $(39.9 \mathrm{~cm})$ and $11.1 \mathrm{in} .(28.2 \mathrm{~cm})$, respectively, vs. an average of 12.0 in. $(30.5 \mathrm{~cm})$ and 7.0 in. (17.8 $\mathrm{cm}$ ), respectively, for the other anthropometric categories. This suggests that a generally accepted ladder width standard of 15 in. $(38.1 \mathrm{~cm})$ is adequate for all but short-heavy climbers.

\section{Joint moments}

The joint moments are presented in terms of: (1) upper limb joint moments (elbow and shoulder); and (2) lower limb moments (hip, knee, and ankle). The moments are presented as a percent of the subject maximum static muscle strength capability at a 90 deg included angle (approximating the angle at which maximum joint moments were observed during the climbing activity).

The analysis disclosed that ladder slant explained $29 \%$ of the variation in mean elbow moment and $9 \%$ of the variation in mean ankle moment. Ladder slant was significant at 0.001 in both of these cases. The time-into-cycle explained between 8 and $27 \%$ of the variation in upper and lower limb moments and was significant at 0.001 in each case. Rung separation, climbing speed, and climbing direction, were generally not significant. The effect of anthropometry was inconsistent and unclear. The major variation in the upper and lower limb joint moments are illustrated on Figs. 6 and 7 respectively.

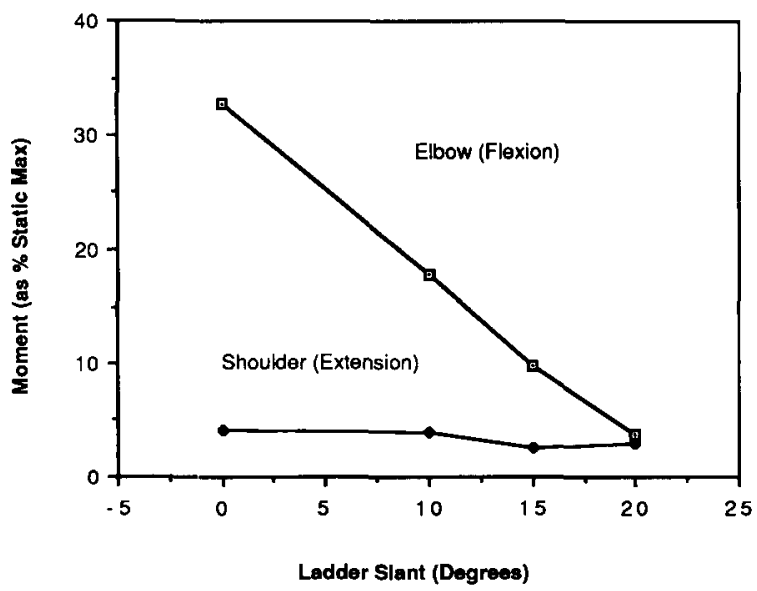

Fig. 6. Elbow and shoulder moment (as percent of static maximum) by ladder slant.

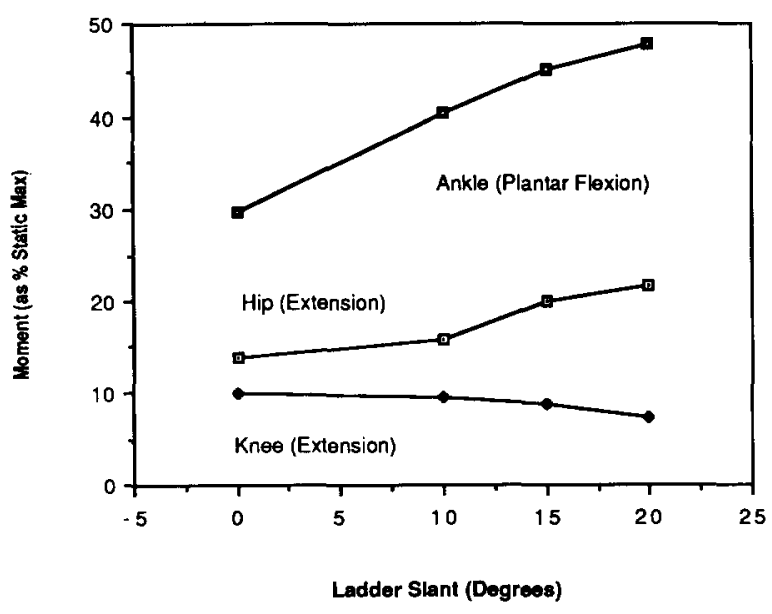

Fig. 7. Hip, knee and ankle moment (as percent of static maximum) by ladder slant.

As noted on Fig. 6, the mean shoulder moment was relatively small and did not vary significantly with ladder slant, while the mean elbow flexion moment varied from $33 \%$ of maximum for the vertical ladder ( 0 deg slant) to $4 \%$ for the ladder at a 20 deg slant. A further analysis of these moments for the vertical ladder indicates that the elbow flexion moment reaches a peak of $45 \%$ of maximum during the one-limb phase of the vertical climbing activity, and the shoulder extension moment reaches a peak of $15 \%$ of maximum during the two-limb phase of the vertical climbing activity.

The variation in lower-limb joint moments is shown on Fig. 7. The mean hip and knee moments remained relatively low while the mean ankle moment ranged from a low of $30 \%$ of the subject maximum for the vertical ladder to nearly $50 \%$ at $20 \mathrm{deg}$ slant. A further analysis of these moments at the $20 \mathrm{deg}$ slant indicated that the knee extension, hip extension and ankle plantar flexion moments reached peaks of 15,30 , and $60 \%$ of maximum, respectively, during the one-limb phase of the climbing activity on ladders slanted at $20 \mathrm{deg}$. The high required ankle moment indicates that a toe clearance behind the ladder rung of $6.1 \mathrm{in}$. $(15.5 \mathrm{~cm})$ is required to allow an average sized user with low (5th percentile) strength to generate the ankle torque required to support the body (Stobbe, 1982). This is required to prevent ankle dorsi flexion and downward slip of the foot. 


\section{Low back hazard analysis}

The low back hazard is estimated by the forces at the L5/S1 disc predicted by the biomechanical model, and by the measured IEMG activity of the torso muscles expressed as a percentage of the maximum IEMG activity in a static maximum exertion.

The analysis disclosed that ladder slant explained $10 \%$ of the variation in mean back compressive force and $35 \%$ of the variation in mean shear force. The time-into-cycle explained $11 \%$ of the variation in mean back compressive force and $7 \%$ of the variation in mean shear force. Both ladder slant and time-into-cycle were significant at 0.001 in these cases. Rung separation, climbing speed, and climbing direction, were generally not significant and explained little of the variation in back forces. There was an anthropometry effect however the effect did not follow any discernable pattern.

The variation in the estimated shear, compressive and total (resultant) forces is illustrated on Fig. 8. These estimated forces are far below the NIOSH action limit of 770 pounds $(3400 \mathrm{~N})$ and well below the NIOSH maximum permissible limit of 1430 pounds $(6400 \mathrm{~N})$ (NIOSH, 1981).

Torso IEMG activity varied primarily as a function of climbing velocity, anthropometry and time-into-cycle. As was the case for the estimated back forces, there was no discernable pattern to

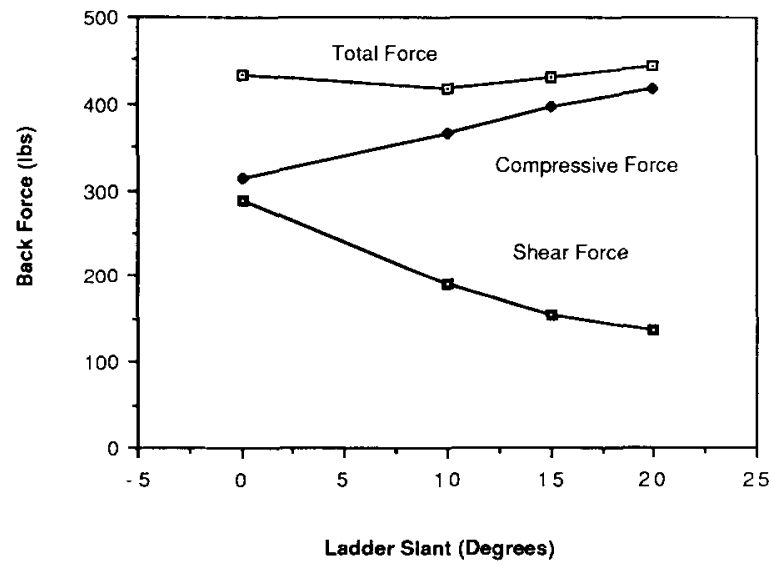

Fig. 8. Estimated back forces by ladder slant. the anthropometry effect. In general the IEMG activity during the fast climb was approximately $35 \%$ higher than during the slow climb. A further analysis of the torso IEMG activity indicates that the peak IEMG of the erector spinae muscles (those with the main contribution to back force) was nearly $100 \%$ of the static maximum during the two-limb propulsive phase for the fast climbing velocity. This suggests a possibility of potentially hazardous low-back forces. It would certainly raise questions as to the endurance limit of these muscles if a climbing activity of long duration (e.g., radio or TV tower) were attempted.

\section{DISCUSSION}

\section{Model validity}

The statistical significance of the correlation between the total of the vertical hand and foot forces vs. the gravity plus inertial force was better than 0.05 in $94 \%$ of the trials. The average coefficient of correlation over all trials was 0.71 . The significance of the correlation between the hip moments calculated from the feet with the hip moments calculated from the hands was better than 0.05 in $56 \%$ of the trials. The average coefficient of correlation over all trials was 0.47 . The significance of the correlation between the modelestimated torso muscle forces and the measured torso IEMG was better than 0.05 in $46 \%$ of the trials for the left erector spinae muscle. The average coefficient of correlation over all trials was 0.19 for the right and 0.28 for the left erector spinae, respectively.

While the correlations are not as high as had been desired, it should be noted that all the correlations were run on a point-by-point basis at 25 $\mathrm{Hz}$ throughout the climbing cycles, so noise in the data would affect the correlations a great deal. It is apparent, however, that the biomechanical model of torso muscle activity requires improvement to predict muscle actions in such highly dynamic activities. It is believed that the relatively high IEMG values show a great deal of torso muscle antagonism which is not included in the biomechanical model. This suggests that the model may underpredict spinal compression forces. 


\section{Slip / Fall hazard analysis}

An analysis of hand and foot force data indicates that, under certain conditions, there may be a potential for hand slip and forward foot slip. The highest one-hand force (nearly $30 \%$ of body weight) and highest hand torque occurred during the use of the vertical ladder. The foot slip potential was highest during the use of vertical ladders where a coefficient of friction in excess of 0.40 may be required to resist forward slip. The generally accepted ladder width standard of 15 in. (38.1 $\mathrm{cm})$ appears to be wide enough to allow all but short-heavy climbers to use their preferred posture.

The required joint moments do not appear to present a significant slip/fall hazard for climbers without musculoskeletal limitations in the conditions observed in this study. The peak required moments at the upper limb articulations were highest during the use of the vertical ladder, while the moments at the lower limb articulations were highest during the use of the slanted ladder. The shoulder moments remained relatively low for all conditions studied, but during the use of the vertical ladder the peak elbow moment was approximately $45 \%$ of maximum strength. During the use of the ladder slanted at $20 \mathrm{deg}$ the peak knee, hip, and ankle moments were approximately 15, 30 and $60 \%$ of subject static maximum, respectively. These exertions were of less than one second duration and are cyclic in nature, thus reducing the potential for localized fatigue except in long periods of climbing.

The relatively high ankle torque requirement for the ladder slanted at 20 deg indicates the need for a minimum toe clearance behind the ladder rungs of approximately $6.1 \mathrm{in} .(15.5 \mathrm{~cm})$ to allow for the generation of adequate ankle plantar flexion moment.

In summary, the most severe slip/fall hazard due to the forces at the hands and feet was determined to be during the use of the vertical ladder, while the highest lower limb articulation moment requirements were for ladders slanted at $20 \mathrm{deg}$.

\section{Low back hazard analysis}

The IEMG activity of the erector spinae muscles was found to be influenced primarily by the speed of the climbing activity, and the time-into-cycle. The peak IEMG activity of the torso muscles occurred during the two-foot propulsive stage of the faster climbing activity and approached $100 \%$ of the subject's static strength value. The IEMG activity of the torso muscles indicated a considerably higher hazard to the back than did the model-estimated back forces. The back compressive and shear forces may be significantly underestimated in the model due to a lack of consideration of antagonist, stabilizing muscle activity demonstrated during the climbing activities. The high measured IEMG levels suggest that climbers who have a history of low-back problems should be encouraged to develop a climbing strategy which minimizes this hazard (possibly by slow steady climbing with frequent rests).

\section{ACKNOWLEDGEMENT}

This research was supported by the Association of American Railroads and the National Institute for Occupational Safety and Health.

\section{REFERENCES}

American National Standards Institute, Inc. (ANSI), 1983. Rationales for ANSI A14.1-1981 (Wood Ladders), A14.21981 (Metal Ladders), and A14.5-1981 (Reinforced Plastic Ladders).

Bresler, B. and Frankel, J.P., 1948. The Forces and Moments in the Leg During Level Walking. The American Society of Mechanical Engineers.

Chaffin, D.B. and Andersson, G., 1984. Occupational Biomechanics. Wiley, New York.

Chaffin, D.B. and Stobbe, T.J., 1979. Ergonomic considerations related to selected fall prevention aspects of scaffolds and ladders as presented in OSHA Standard 29 CFR 1910 Subpart D. The University of Michigan, Department of Industrial and Operations, Technical Report.

Jack, D., Estes, H. and Grace, P., May 1978. Operator Grip Strength. Ford Automotive Safety Office.

McClellan, J.H. and Parks, T.W., 1973. A Unified Approach to the Design of Optimum FIR Linear-Phase Digital Filters. IEEE Trans. Circuit Theory, CT 20 (6): 697-701.

National Health Survey, NCHS, 1979. Weight and Height of Adults 18-74 Years of Age, United States, 1971-1974. U.S. Department of Health, Education, and Welfare, Series 11, No. 211.

National Institute for Occupational Safety and Health (NIOSH), 1981. Work Practices Guide for Manual Lifting. 
Pheasant, S. and O'Neill, D., 1975. Performance in gripping and turning-A study in hand/handle effectiveness. Appl. Ergon., 7: 205-208.

Safety Sciences, 1978. Occupational Fall Accident Patterns Supplementary Data. Prepared for National Institute for Occupational Safety and Health, Contract No. 210-75-0017.

Schultz, A.B. and Andersson, G.B., 1981. Analysis of loads on the lumbar spine. Spine, 6(1): 76-82.

Snyder, R.G., 1977. Occupational falls. Report No. UM-HSRI77-51, National Institute for Occupational Safety and Health.

Stobbe, T., 1982. The development of a practical strength testing program for industry. Unpublished Ph.D. Thesis (Industrial Engineering), The University of Michigan, Ann Arbor, MI, U.S.A.

\section{APPENDIX A}

The method of joint method estimation used in this research is shown in Fig. A.1.

\section{List of symbols}

$I_{i} \quad$ rotational moment of inertia of link $i$ about its CM

(REA) reactive forces and moments

(RES) resultant forces and moments

$\bar{F}_{j}, \bar{M}_{j}$ forces and moments at joint $j$

$m_{j} \quad$ mass of link $i$

$\bar{c}_{i} \quad$ location of $\mathrm{CM}$ of link $i$

$j \quad$ location of joint $j$

$\ddot{\bar{c}}_{i} \quad$ acceleration of mass center of link $i$

$\ddot{\bar{\theta}}_{i} \quad$ angular acceleration of link $i$ about joint $j+1$

$\bar{g} \quad$ force of gravity

The forces and moments at each joint can be calculated as shown below:

\section{Forces}

1. (REA) $\bar{F}_{j+1}+(\mathrm{RES}) \bar{F}_{j}+m_{i} \bar{g}-m_{i} \ddot{\bar{c}}_{i}=0$

$2(\operatorname{RES}) \bar{F}_{j+1}=-(\mathrm{REA}) \bar{F}_{j+1}$

$\bullet(\mathrm{RES}) \bar{F}_{j+1}=(\mathrm{RES}) \bar{F}_{j}+m_{i} \bar{g}-m_{i} \ddot{\bar{c}}_{i}$

\section{Moments}

1. (REA) $\bar{M}_{j+1}+(\mathrm{RES}) \bar{M}_{j}$

$$
\begin{aligned}
& +\left[(\operatorname{RES}) \bar{F}_{j}\right] \times[\overline{j+1} \rightarrow \bar{j}]-I_{i} \ddot{\bar{\theta}}_{i} \\
& -\left[m_{i} \ddot{\bar{c}}_{i}\right] \times\left[\overline{j+1} \rightarrow \bar{c}_{i}\right] \\
& +\left[m_{i} \bar{g}\right] \times\left[\overline{j+1} \rightarrow \bar{c}_{i}\right]=0
\end{aligned}
$$

2. (RES) $\bar{M}_{j+1}=-(\mathrm{REA}) \bar{M}_{j+1}$

$$
\begin{aligned}
& \because(\operatorname{RES}) \bar{M}_{j+1} \\
& =(\operatorname{RES}) \bar{M}_{j}+\left[(\operatorname{RES}) \bar{F}_{j}\right] \times[\overline{j+1} \rightarrow \bar{j}] \\
& \quad+m_{i}\left[\bar{g}-\ddot{\bar{c}}_{i}\right] \times\left[\overline{j+1} \rightarrow \bar{c}_{i}\right]-I_{i} \ddot{\bar{\theta}}_{i}
\end{aligned}
$$

where $[j+1 \rightarrow j]=$ vector distance from point $j$ +1 to point $j$.

\section{APPENDIX B}

The three dimensional torso model used in this research can be represented as shown in Fig. B.1

\section{List of symbols}

$\mathrm{IO}_{\mathrm{L}}, \mathrm{IO}_{\mathrm{R}} \quad$ left and right internal oblique muscle forces

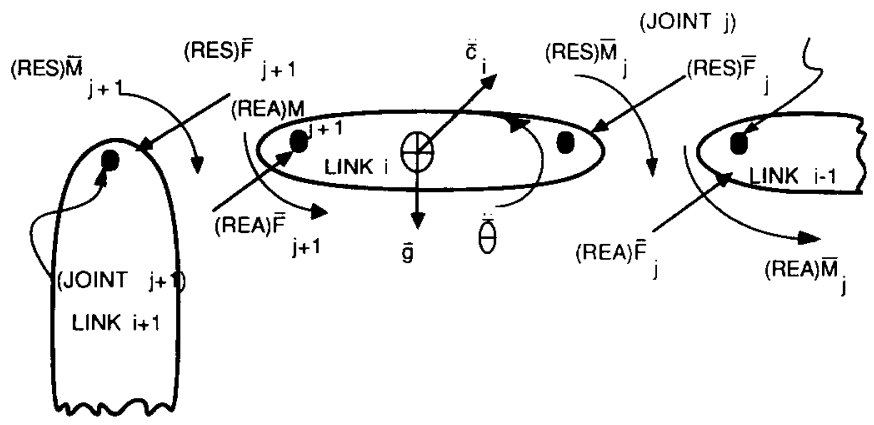

Fig. A.1. The joint moment estimation. 


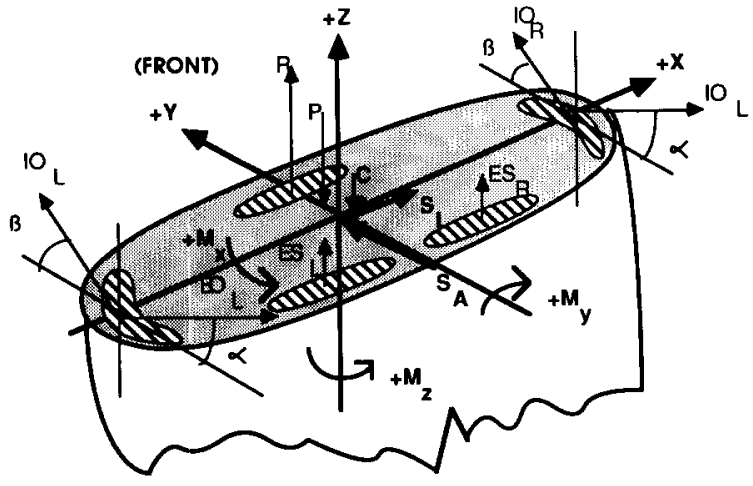

Fig. B.1. The three dimensional torso model.

$\mathrm{EO}_{\mathrm{L}}, \mathrm{EO}_{\mathrm{R}} \quad$ left and right external oblique muscle forces

$\mathrm{ES}_{\mathrm{L}}, \mathrm{ES}_{\mathrm{R}} \quad$ left and right erector spinae muscle forces

$R \quad$ rectus abdominus muscle force

$P \quad$ abdominal pressure force

$C \quad$ compressive force on $\mathrm{L} 5 / \mathrm{S} 1$ disk

$S_{\mathrm{A}} \quad$ anterior-posterior shear force (in cutting plane of torso)

$S_{\mathrm{L}} \quad$ lateral shear force

$\alpha, \beta \quad$ angles between IO and EO and cutting plane

An analysis of this torso model indicates that there are 10 unknowns and 6 equations of equilibrium:

Compressive and shear forces at the L5/S1: $C$, $S_{\mathrm{A}}, S_{\mathrm{L}}$

Muscle forces: $\mathrm{IO}_{\mathrm{L}}, \mathrm{IO}_{\mathrm{R}}, \mathrm{EO}_{\mathrm{L}}, \mathrm{EO}_{\mathrm{R}}, \mathrm{ES}_{\mathrm{L}}, \mathrm{ES}_{\mathrm{R}}$, $R$

Abdominal pressure force: $P$

$P$ can be calculated, leaving 10 unknowns and the following 6 equations of equilibrium:

Resultant $F_{X}=S_{\mathrm{L}}=0$

Resultant $F_{Y}=S_{\mathrm{A}}+\mathrm{IO}_{\mathrm{L}} \cos \beta-\mathrm{EO}_{\mathrm{L}} \cos \alpha+$ $\mathrm{IO}_{\mathrm{R}} \cos \beta-\mathrm{EO}_{\mathrm{R}} \cos \alpha$

Resultant $F_{Z}=R+\mathrm{ES}_{\mathrm{L}}+\mathrm{ES}_{\mathrm{R}}+\left(\mathrm{IO}_{\mathrm{L}}+\mathrm{IO}_{\mathrm{R}}\right) \times$ $\sin \beta+\left(\mathrm{EO}_{\mathrm{L}}+\mathrm{EO}_{\mathrm{R}}\right) \sin \alpha-P$

$-C$
Resultant $M_{X}=Y_{R}(R)-Y_{P}(P)-Y_{E}\left(\mathrm{ES}_{\mathrm{L}}+\right.$ $\left.\mathrm{ES}_{\mathrm{R}}\right)$

Resultant $M_{Y}=X_{O}\left(\mathrm{IO}_{\mathrm{L}} \sin \beta\right)-X_{O}\left(\mathrm{EO}_{\mathrm{L}} \sin \alpha\right)$ $+X_{E}\left(\mathrm{ES}_{\mathrm{L}}\right)-X_{O}\left(\mathrm{IO}_{\mathrm{R}} \sin \beta\right)$

$-X_{O}\left(\mathrm{EO}_{\mathrm{R}} \sin \alpha\right)-X_{E}\left(\mathrm{ES}_{\mathrm{R}}\right)$

Resultant $=X_{O}\left(\mathrm{EO}_{\mathrm{L}} \cos \alpha\right)-X_{O}\left(\mathrm{EO}_{\mathrm{R}} \cos \alpha\right)$ $+X_{O}\left(\mathrm{IO}_{\mathrm{R}} \cos \beta\right)-X_{O}\left(\mathrm{IO}_{\mathrm{L}} \cos \beta\right)$

where: $X, Y=$ distance from $\mathrm{L} 5 / \mathrm{S} 1$ to force lines of action (in cutting plane of torso). The subscripts to $X$ and $Y$ indicate forces generated by: $E=$ erector spinae, $O=$ obliques, $R=$ rectus abdominus, and $P=$ abdominal pressure force.

Using linear programming, the ten unknowns are calculated as follows:

Minimize: $C=R+\mathrm{ES}_{\mathrm{L}}+\mathrm{ES}_{\mathrm{R}}+\left(\mathrm{IO}_{\mathrm{L}}+\mathrm{IO}_{\mathrm{R}}\right) \sin$ $\beta+\left(\mathrm{EO}_{\mathrm{L}}+\mathrm{EO}_{\mathrm{R}}\right) \sin \alpha-P$

Such that:

1. Moments are equal

$$
\begin{aligned}
M_{X}= & Y_{R}(R)-Y(P)-Y_{E}\left(\mathrm{ES}_{\mathrm{L}}+\mathrm{ES}_{\mathrm{R}}\right)=0 \\
M_{Y}= & X_{O}\left(\mathrm{IO}_{\mathrm{L}} \sin \beta\right)+X_{O}\left(\mathrm{EO}_{\mathrm{L}} \sin \alpha\right) \\
& +X_{E}\left(\mathrm{ES}_{\mathrm{L}}\right)-X_{O}\left(\mathrm{IO}_{\mathrm{R}} \sin \beta\right) \\
& -X_{O}\left(\mathrm{EO}_{\mathrm{R}} \sin \alpha\right)-X_{E}\left(\mathrm{ES}_{\mathrm{R}}\right)=0 \\
M_{Z}= & X_{O}\left(\mathrm{EO}_{\mathrm{L}} \cos \alpha\right)-X_{O}\left(\mathrm{EO}_{\mathrm{R}} \cos \alpha\right) \\
& +X_{O}\left(\mathrm{IO}_{\mathrm{R}} \cos \beta\right)-X_{O}\left(\mathrm{IO}_{\mathrm{L}} \cos \beta\right)=0
\end{aligned}
$$

2. Muscle contraction intensity $\leqslant 100 \mathrm{~N} / \mathrm{cm}^{2}$

$$
\begin{aligned}
& \mathrm{IO}_{\mathrm{L}}, \mathrm{IO}_{\mathrm{R}} \leqslant 100 \mathrm{~N} / \mathrm{cm}^{2} \\
& \mathrm{EO}_{\mathrm{L}}, \mathrm{EO}_{\mathrm{R}} \leqslant 100 \mathrm{~N} / \mathrm{cm}^{2} \\
& \mathrm{ES} \\
& R \leqslant 100 \mathrm{ES} / \mathrm{cm}^{2} \leqslant 100 \mathrm{~N} / \mathrm{cm}^{2}
\end{aligned}
$$

(In order to minimize the effect of the muscle with the largest moment arm reaching maximum before any other muscles enter into the model, start at 10 $\mathrm{N} / \mathrm{cm}$ and iterate in 10 newton increments until a solution is found.)

3. Muscles only act in contraction

$$
\begin{aligned}
& \mathrm{IO}_{\mathrm{L}}, \mathrm{IO}_{\mathrm{R}} \geqslant 0 \mathrm{~N} / \mathrm{cm}^{2} \\
& \mathrm{EO}_{\mathrm{L}}, \mathrm{EO}_{\mathrm{R}} \geqslant 0 \mathrm{~N} / \mathrm{cm}^{2} \\
& \mathrm{ES}_{\mathrm{L}}, \mathrm{ES}_{\mathrm{R}} \geqslant 0 \mathrm{~N} / \mathrm{cm}^{2} \\
& R \quad \geqslant 0 \mathrm{~N} / \mathrm{cm}^{2}
\end{aligned}
$$

